\title{
Biogenic Synthesis, Characterization and Antibacterial Properties of Silver Nanoparticles against Human Pathogens
}

Mohammad Shahzad Tufail ${ }^{1}$, Iram Liaqat ${ }^{1 *}$, Saiqa Andleeb ${ }^{2}$, Sajida Naseem ${ }^{3}$, Urooj Zafar ${ }^{4}$, Ayesha Sadiqa ${ }^{5}$, Irfana Liaqat ${ }^{1}$, Nazish Mazhar Ali ${ }^{1}$, Asia Bibi $^{6}$, Najma Arshad ${ }^{7}$, and Gulbeena Saleem ${ }^{8}$

${ }^{1}$ Microbiology Lab, Department of Zoology, GC University, Lahore, PAKISTAN
2 Department of Zoology, University of Azad Jammu and Kashmir, PAKISTAN
${ }^{3}$ Department of Zoology, University of Education, Lower Mall Campus, Lahore, PAKISTAN
${ }^{4}$ Department of Microbiology, University of Karachi, Karachi, PAKISTAN
${ }^{5}$ Department of Chemistry, University of Lahore, Lahore, PAKISTAN
${ }^{6}$ Department of Zoology, The Women University, Multan, PAKISTAN
7 Department of Zoology, The University of Lahore, Lahore, PAKISTAN
${ }^{8}$ Department of Pathology, University of Veterinary and Animal Sciences, Lahore, PAKISTAN

\begin{abstract}
Biogenic synthesis of silver nanoparticles (AgNPs) is more eco-friendly and cost-effective approach as compared to the conventional chemical synthesis. Biologically synthesized AgNPs have been proved as therapeutically effective and valuable compounds. In this study, the four bacterial strains Escherichia coli (MT448673), Pseudomonas aeruginosa (MN900691), Bacillus subtilis (MN900684) and Bacillus licheniformis (MN900686) were used for the biogenic synthesis of AgNPs. Agar well diffusion assay revealed to determine the antibacterial activity of all biogenically synthesized AGNPs showed that $P$. aeruginosa AgNPs possessed significantly high $(p<0.05)$ antibacterial potential against all tested isolates. The one-way ANOVA test showed that that $P$. aeruginosa AgNPs showed significantly $(p<0.05)$ larger zones of inhibition (ZOI: 19 to $22 \mathrm{~mm}$ ) compared to the positive control (rifampicin: $50 \mu \mathrm{g} / \mathrm{mL}$ ) while no ZOI was observed against negative control (Dimethyl sulfoxide: DMSO). Minimum inhibitory concentration (MIC) and minimum bactericidal concentration (MBC) concentration against four test strains also showed that among all biogenically synthesized NPs, $P$. aeruginosa AgNPs showed effective MIC (3.3-3.6 $\mu \mathrm{g} / \mathrm{mL})$ and MBC (4.3-4.6 $\mu \mathrm{g} / \mathrm{mL}$ ). Hence, $P$. aeruginosa AGNPs were characterized using visual $\mathrm{UV}$ vis-spectroscopy, $\mathrm{X}$ ray diffractometer (XRD), fourier transform infrared (FTIR) and scanning electron microscopy (SEM). The formation of peak around $430 \mathrm{~nm}$ indicated the formation of AgNPs while the FTIR confirmed the involvement of biological molecules in the formation of nanoparticles (NPs). SEM revealed that the NPs were of approximately $40 \mathrm{~nm}$. Overall, this study suggested that the biogenically synthesized nanoparticles could be utilized as effective antimicrobial agents for effective disease control.
\end{abstract}

Key words: biogenic silver nanoparticles, tube dilution method, agar well diffusion method, antibacterial activity, MIC and MBC determination

\section{Introduction}

Nanotechnology is the emerging field of science with lots of benefits to humans, animals and nature. Out of many excellent findings of nanotechnology, the nanoparticles (NPs) are very much beneficial ${ }^{1)}$. With the advancement in nanotechnology, humans have gained the ability to synthesize nanoparticles in the labs ${ }^{2)}$. The particles having nanometers size are known as NPs. There are many kinds of metallic and non-metallic NPs synthesized using metals such as $\mathrm{Au}, \mathrm{Ag}, \mathrm{Ce}, \mathrm{Pt}, \mathrm{Pd}$ and $\mathrm{Zn}^{3)}$, but most important are silver nanoparticles (AgNPs). The AgNPs have extensively been studied for their activities particularly antimicrobial activi-

\footnotetext{
*Correspondence to: Iram Liaqat, Microbiology Lab, Department of Zoology, GC University, Lahore, PAKISTAN

E-mail: iramliaq@ hotmail.com ORCID ID: https://orcid.org/0000-0002-4638-8253

ORCID ID: https://orcid.org/0000-0002-0524-3656 (MST), https://orcid.org/0000-0001-7888-6444 (SA), https://orcid.org/0000-0002-9211-2944 (SN), https://orcid.org/0000-0001-6506-1080 (UZ), https://orcid. org/0000-0003-2900-5940 (AS), https://orcid.org/0000-0001-5542-6998 (IL), https://orcid.org/0000-00018740-4515 (NMA), https://orcid.org/0000-0001-8181-0723 (AB), https://orcid.org/0000-0002-0244-6757 (NA) Accepted October 13, 2021 (received for review September 24, 2021)
}

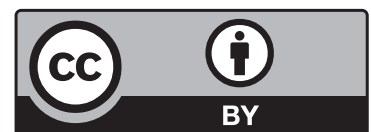


ties ${ }^{4,5)}$ and emerging as promising nano antibiotics now a days $^{6)}$. Because of their broad-spectrum activities, AgNPs grab great attention in the field of biomedical, medicine, agriculture, insect control and several other industries ${ }^{7)}$. By using an ecofriendly approach, AgNPs applications have been increased in preparation of large number of products such as pests, electronic devices and in controlling microbe's growth and infection ${ }^{8,9)}$. Silver nanoparticles (AgNPs) are most commercialized among inorganic nanoparticles. They are nontoxic, safe inorganic antibacterial agent used for centuries and has great potential to kill disease causing microorganisms.

The use of silver as suspension and in nano-particulate form has a dramatic revival in nanotechnology. It has eminence antibacterial potency against human pathogens. The main task in nanoparticles synthesis is the control of their physical properties like uniform particle size, similar shape, chemical composition, morphology and crystal structure. The reduced effectiveness of drugs, antibiotics against the pathogenic bacteria, particularly against multi-drug resistance (MDR) bacteria could be the major threat to the life of the human being ${ }^{1,10)}$. AgNPs have very strong antibacterial activity against the human pathogens, because of their effectiveness against most of the microbial pathogens, microorganisms have been probed as potential bio-factories for metallic nanoparticles synthesis such as silver, copper, zinc and gold (biogenic synthesis) ${ }^{11)}$.

Moreover, the antibacterial activity of biogenic nanoparticles in combination with antibiotics signifies their importance in combating multi-drug resistant(MDR) pathogenic bacteria in planktonic ${ }^{12}$ and biofilm mode (microorganisms embedded in elf produced polymeric matrix $)^{13)}$. It was also observed that drug-loaded silver nanoparticles (Ciprofloxacin $+10 \mathrm{mM}$ ) showed a stronger antibacterial potential than the synthesized silver nanoparticles and ciprofloxacin alone to restrict the development of E. coli and E. aerogene $^{14)}$. Biogenically synthesized nanoparticles are easy to produce biocompatible, economic, environmental friendly and offer different catalytic abilities compared to chemically synthesized ones. They have anticancer and antioxidant properties. Furthermore, they are naturally stabilized, as the natural organic material (citrate, sodium dodecyl sulfate) of bacteria work as natural capping layers surrounding the biogenic nanoparticles, make these active, stable and reusable ${ }^{1,12,15,16)}$. These act as promising antimicrobial agent due to their long term stability and biocompatibility $^{17)}$.

The application of biogenic AgNPs has been demonstrated since it arrests the growth and multiplication of many bacteria such as Bacillus cereus, B. subtilis, Staphylococcus aureus, Citrobacter koseri, Salmonella typhii, P. aeruginosa, E. coli, Klebsiella pneumoniae, and Candida albicans by binding $\mathrm{Ag} / \mathrm{Ag}^{+}$with the biomolecules present in the microbial cells. It has been suggested that biogenic
AgNPs produce reactive oxygen species and free radicals which cause cell death through apoptosis and prevent their replication. Since AgNPs are smaller than the microorganisms, they diffuse into cell and rupture the cell wall which has been shown from SEM. It has also been observed that smaller nanoparticles are more effective than the bigger ones $^{1,18)}$.

In this study, microbial synthesis of AgNPs was investigated by using culture supernatant of the bacterial strains E. coli(MT448673), P. aeruginosa (MN900691), B. subtilis (MN900684) and B. licheniformis (MN900686), as a reducing agent. The biogenically synthesized AgNPs was further characterized for the antibacterial potency against four human pathogenic bacteria (both Gram negative and Gram positive) using agar well diffusion method. The $P$. aeruginosa AgNPs showed significant antibacterial potential, hence were further characterized by UV-vis spectroscopy, $\mathrm{X}$ ray diffraction (XRD), scanning electron microscopy (SEM) and fourier transform infrared spectroscopy (FTIR).

\section{Materials and Methods}

\subsection{Test microorganisms}

Four human pathogenic bacteria (both Gram negative and Gram positive) such as E. coli (MT448673), P. aeruginosa (MN900691), B. subtilis (MN900684) and B. licheniformis (MN900686) were obtained from Microbiology lab, Government College University, Lahore and used in the current study.

\subsection{Chemicals and reagents}

The chemicals, media, reagents and $\mathrm{AgNO}_{3}$ used during experiments were highly pure and up to the analytical grade. The chemicals including silver nitrate (Merck, Germany), Luria bertani(LB) agar and LB broth were purchased from Sigma-Aldrich, USA.

\subsection{Preparation of supernatant}

Luria bertani (LB) broth was prepared by dissolving $5.0 \mathrm{~g}$ Sodium chloride, $5.0 \mathrm{~g}$ peptone; $3.0 \mathrm{~g}$ yeast extract in 500 $\mathrm{mL}$ distilled water, which after adjusting $\mathrm{pH}$ was made up to 1 liter. The prepared LB was sterilized by autoclaving at $121^{\circ} \mathrm{C}$ for 15 minutes at $15 \mathrm{Ib}$ and inoculated with $100 \mu \mathrm{L}$ (OD: $1 \pm 0.2$ ) fresh cultures of E. coli, P. aeruginosa, $B$. subtilis and B. licheniformis, separately. The culture flasks were incubated for $24 \mathrm{~h}$ in incubator at $37^{\circ} \mathrm{C}$ at a rotatory shaker (2g-force). Following incubation, the bacterial cultures were centrifuged at $10000 \mathrm{rpm}$ for $10 \mathrm{~min}$ twice. The supernatants were saved for further study.

\subsection{Biosynthesis of silver nanoparticles}

For synthesis of AgNPs, each supernatant was mixed with $10 \mathrm{mM}$ solution of $\mathrm{AgNO}_{3}$, in 2:1 (supernatant: $\mathrm{AgNO}_{3}$ 
solution) while two control flasks, each with $\mathrm{AgNO}_{3}(10$ $\mathrm{mM}$ ) and bacterial culture separately were run in parallel. The prepared solutions were incubated for $72 \mathrm{~h}$ on rotatory shaker at $2 \mathrm{~g}$-force at $37^{\circ} \mathrm{C}$. All the solutions were kept in dark to prevent photochemical reaction during the experiment. After three days, flasks having supernatants and $\mathrm{AgNO}_{3}$ turned showed color change from yellow solution to brown confirming synthesis of AgNPs. No colour change was observed in control flask. The cultures were centrifuged at 3g-force for 10 minutes, the pellet was discarded and the supernatant was saved for further characterization.

\subsection{Antibacterial activity of AgNPs}

The antibacterial activity of AgNPs was analyzed through agar well diffusion method against the test pathogens i.e., E. coli, P. aeruginosa, B. subtilis and B. licheniformis ${ }^{19-22)}$. The Muller Hinton agar plates were prepared and well of 6 $\mathrm{mm}$ diameter were made using sterile cork borer. The test pathogens culture was adjusted to $0.5 \mathrm{McF}$ arland turbidity standard and was spread on the media plate uniformly. The $100 \mu \mathrm{L}$ of $\operatorname{AgNPs}(1 \mathrm{mg} / \mathrm{mL})$ was added into each well. DMSO, rifampicin $(50 \mu \mathrm{g} / \mathrm{mL})$ and $\mathrm{AgNO}_{3}$ were used as controls. The plates were kept at room temperature for one hour. Afterwards, plates were incubated at $37^{\circ} \mathrm{C}$ for $24 \mathrm{~h}$. Following incubation period, the clear zones around the wells were taken as zone of inhibition(ZOI) and were recorded in millimeter $(\mathrm{mm})$.

\subsection{Determination of minimum inhibitory concentration} (MIC) and minimum bactericidal concentration (MBC)

MIC and MBC of AgNPs were measured using tube dilution method following Liaqat et $a l^{23)}$ with slight modifications. In brief, $3 \mathrm{~mL}$ of freshly prepared nutrient broth was added into the test tubes. About $10 \mu \mathrm{L}$ of bacterial culture which (adjusted to $0.5 \mathrm{McF}$ arland turbidity standard) was added to the tubes containing broth. The test tubes were supplied with various concentrations $(3-12 \mu \mathrm{g} / \mathrm{mL})$ of AgNPs and incubated at $37^{\circ} \mathrm{C}$ for $24 \mathrm{~h}$. Controls having $\mathrm{AgNO}_{3}$ and $\mathrm{LB}$ medium were run in parallel. Following incubation, MIC was measured by considering the lowest possible concentration that inhibited the bacterial growth visually, while the $\mathrm{MBC}$ was determined by spreading the lowest MIC on media plates which killed $99.9 \%$ of bacteria.

\subsection{Characterization of $P$. aeruginosa AgNPs}

P. aeruginosa synthesized AgNPs showed excellent antibacterial potential hence subjected to the further characterization via UV-Visible spectroscopy, FTIR, SEM, and $\mathrm{XRD}$ in order to confirm the formation and specificity (size, shape and peak) of AgNPs.

\subsubsection{UV-Visible spectroscopy}

The $P$. aeruginosa AgNPs supernatant was qualitatively analyzed by UV-visible spectroscopy using AE-S70-1U UVvisible spectrophotometer and $\mathrm{AgNO}_{3}$ solution was used as control. UV-vis spectrophotometer from 300 to $770 \mathrm{~nm}$ operated at a resolution of $1 \mathrm{~nm}$ was used as a function of wavelength for spectral analysis of AgNPs. Occurrence of peak between 400-470 nm showed formation of AgNPs and reduction of silver nitrate.

2.7.2 Fourier transform-infrared (FTIR) spectroscopy

The FTIR spectroscopy of $P$. aeruginosa AgNPs was performed in order to check the influence of bio-molecules which were responsible for the reduction, stabilization and capping of AgNPs as well as to determine the functional groups of the AgNPs. The completely dried samples of AgNPs were used in order to perform FTIR. The spectrum was recorded on FTIR (IR Prestige-21 (P/N 206-72010. SHI$\mathrm{MADZU})$ ) in the transmission range of $4000-500 \mathrm{~cm}^{-124)}$.

2.7.3 Scanning Electron Microscopy (SEM)

The size and morphology of the P. aeruginosa AgNPs was analyzed by coating the air dried AgNPs and observing under scanning electron microscope (EM6200).

2.7.4 X-ray diffraction (XRD)

Formation of $P$. aeruginosa AgNPs was further checked by XRD technique using an X-ray diffractometer (Phillips PW 1729/40) operated at $40 \mathrm{kV}, 40 \mathrm{~mA}$, step size of 0.2 , over the $2 \theta$ range of $20-80^{\circ}$. Glass slides coated with AgNPs were tested following manufacturer guidelines.

\subsection{Statistical analysis}

All experiments were performed in triplicates. Microsoft Excel 2019 was used to draw graphs while SPSS version 10 was used to calculate means, standard error and one way ANOVA test followed by Tureky's test was used to determine the significance level at $p \leq 0.05^{23)}$. The figure of FTIR data was made using origin 2019A (8.5.1). The pictures of SEM and XRD were derived from one replicate.

\section{Results}

\subsection{Synthesis of AgNPs}

Biogenic synthesis of AgNPs by using four bacterial isolates (E. coli, P. aeruginosa, B. subtilis and B. licheniformis) was confirmed by the change of color from pale yellow to brown after 72 hours incubation compared to the two controls. The formation of AgNPs indicated that certain reducing agent released by the tested bacteria are actually involved in the reduction of $\mathrm{Ag}^{+}$ions to AgNPs. In control group, the reduction of $\mathrm{Ag}^{+}$ions did not occur due to the absence of reducing agent produced by bacteria, hence no color change was observed (Fig. S1).

\subsection{Antibacterial activity of AgNPs}

Biogenically synthesized AgNPs showed significant antibacterial activity against human pathogenic strains such as E. coli, P. aeruginosa, B. subtilis and B. licheniformis. E. coli synthesized AgNPs showed $17.6 \mathrm{~mm}$ ZOI against $E$. 
coli, $18.3 \mathrm{~mm}$ against $P$. aeruginosa, $19.6 \mathrm{~mm}$ against $B$. subtilis and $16 \mathrm{~mm}$ against $B$. licheniformis. P. aeruginosa synthesized AgNPs showed $19 \mathrm{~mm}$ ZOI against $E$. coli, $20.3 \mathrm{~mm}$ against $P$. aeruginosa, $21.6 \mathrm{~mm}$ against $B$. subtilis and $22.5 \mathrm{~mm}$ against $B$. licheniformis. B. subtilis synthesized AgNPs showed $16.6 \mathrm{~mm}$ ZOI against E. coli, 15.6 $\mathrm{mm}$ against $P$. aeruginosa, $17.3 \mathrm{~mm}$ against $B$. subtilis and $15 \mathrm{~mm}$ against $B$. licheniformis. B. licheniformis synthesized AgNPs showed $17.6 \mathrm{~mm}$ ZOI against $E$. coli, 20 $\mathrm{mm}$ against $P$. aeruginosa, $19 \mathrm{~mm}$ against $B$. subtilis and $17 \mathrm{~mm}$ against $B$. licheniformis. On the other hand, positive control (rifampicin $50 \mu \mathrm{g} / \mathrm{mL}$ ) showed $5.0 \mathrm{~mm}$ ZOI against $E$. coli, $6.0 \mathrm{~mm}$ against $P$. aeruginosa, $7.0 \mathrm{~mm}$ against $B$. subtilis and $6.3 \mathrm{~mm}$ ZOI against $B$. lichenifor- mis. P. aeruginosa AgNPs showed highest ZOI(19-22 $\mathrm{mm})$ against all tested human strains. The negative control (DMSO) was unable to inhibit the growth of any test strain while the positive control(rifampicin) showed 5.0 to 7.0 mm ZOI(Fig. 5 and Table 1). The one-way ANOVA showed that $P$. aeruginosa AgNPs showed significant antibacterial activity $(p<0.05)$ as compared other biogenically synthesized AgNPs and positive control.

\subsection{MIC and MBC determination}

MIC was measured to determine the lowest concentration which is effective to inhibit bacterial growth. It was observed that MIC values of $E$. coli AgNPs ranged from 6.0 to $8.6 \mu \mathrm{g} / \mathrm{mL}$, P. aeruginosa AgNPs from 2.6 to $3.3 \mu \mathrm{g} / \mathrm{mL}$,

Table 1 Antibacterial Activity of Biogenically Synthesized AgNPs.

\begin{tabular}{|c|c|c|c|c|c|c|c|c|}
\hline \multirow{2}{*}{$\begin{array}{l}\mathrm{Sr} \\
\text { No. }\end{array}$} & \multirow[t]{2}{*}{ Strains } & E. coli & P. aeruginosa & B. subtilis & B. licheniformis & $\begin{array}{c}\text { Rifampicin (PC) } \\
(50 \mu \mathrm{g} / \mathrm{mL})\end{array}$ & DMSO (NC) & $\begin{array}{c}\mathrm{AgNO}_{3} \\
(1 \mathrm{mg} / \mathrm{mL})\end{array}$ \\
\hline & & \multicolumn{7}{|c|}{ Zone of inhibition in $\mathrm{mm}(\mathrm{Mean} \pm$ S.E $)$} \\
\hline 1 & $\begin{array}{l}\text { E. coli AgNPs } \\
(100 \mu \mathrm{g} / \mathrm{mL})\end{array}$ & $17.6 \pm 0.33^{\mathrm{c}}$ & $18.3 \pm 0.33^{\text {cd }}$ & $19.6 \pm 0.33^{\mathrm{d}}$ & $16 \pm 0.57^{\mathrm{b}}$ & $5.0 \pm 0^{\mathrm{a}}$ & $0.0 \pm 0^{\mathrm{a}}$ & $2.0 \pm 0^{\mathrm{a}}$ \\
\hline 2 & $\begin{array}{l}\text { P. aeruginosa AgNPs } \\
(100 \mu \mathrm{g} / \mathrm{mL})\end{array}$ & $19.0 \pm 0.57^{\mathrm{c}}$ & $20.3 \pm 0.66^{\mathrm{d}}$ & $21.6 \pm 0.33^{d}$ & $22.5 \pm 0.28^{\mathrm{c}}$ & $6.0 \pm 0.57^{\mathrm{b}}$ & $0 \pm 0^{\mathrm{a}}$ & $2.0 \pm 0.32^{b}$ \\
\hline 3 & $\begin{array}{l}\text { B. subtilis AgNPs } \\
(100 \mu \mathrm{g} / \mathrm{mL})\end{array}$ & $16.6 \pm 0.88^{\mathrm{de}}$ & $15.6 \pm 0.33^{\mathrm{cd}}$ & $17.3 \pm 0.88^{\mathrm{e}}$ & $15.0 \pm 0.57^{\mathrm{c}}$ & $7.0 \pm 0.57^{\mathrm{b}}$ & $0 \pm 0^{\mathrm{a}}$ & $2.0 \pm 0.24^{b}$ \\
\hline 4 & $\begin{array}{l}\text { B. licheniformis } \\
\text { AgNPs }(100 \mu \mathrm{g} / \mathrm{mL})\end{array}$ & $17.6 \pm 0.33^{\mathrm{c}}$ & $20.0 \pm 0^{c}$ & $19.0 \pm 0.57^{\mathrm{c}}$ & $17.0 \pm 0.57^{\mathrm{c}}$ & $6.3 \pm 0.33^{b}$ & $0 \pm 0^{\mathrm{a}}$ & $2.3 \pm 0.25^{\mathrm{b}}$ \\
\hline
\end{tabular}

PC, Positive control; NC, negative control.

Table 2 MIC and MBC of biogenically synthesized AgNPs against test pathogens.

\begin{tabular}{clcc}
\hline Compound & Test Pathogens & MIC $(\mu \mathrm{g} / \mathrm{mL})$ & MBC $(\mu \mathrm{g} / \mathrm{mL})$ \\
\hline \multirow{4}{*}{ E. coli AgNPs } & P. aeruginosa & $8.6^{\mathrm{b}}$ & $11.6^{\mathrm{d}}$ \\
& B. subtilis & $6.0^{\mathrm{a}}$ & $7.0^{\mathrm{a}}$ \\
& B. licheniformis & $6.0^{\mathrm{a}}$ & $10.3^{\mathrm{c}}$ \\
\hline & E. coli & $6.7^{\mathrm{ab}}$ & $8.3^{\mathrm{b}}$ \\
\hline \multirow{5}{*}{ P. aeruginosa AgNPs } & P. aeruginosa & $3.3^{\mathrm{a}}$ & $4.6^{\mathrm{a}}$ \\
& B. subtilis & $3.6^{\mathrm{a}}$ & $4.3^{\mathrm{a}}$ \\
& B. licheniformis & $3.3^{\mathrm{a}}$ & $4.6^{\mathrm{a}}$ \\
\hline & E. coli & $2.6^{\mathrm{a}}$ & $4.6^{\mathrm{a}}$ \\
\hline \multirow{5}{*}{ B. subtilis AgNPs } & P. aeruginosa & $5.6^{\mathrm{ab}}$ & $6.3^{\mathrm{a}}$ \\
& B. subtilis & $6.3^{\mathrm{b}}$ & $6.6^{\mathrm{a}}$ \\
& B. licheniformis & $4.6^{\mathrm{a}}$ & $5.6^{\mathrm{a}}$ \\
& E. coli & $5.6^{\mathrm{ab}}$ & $6.6^{\mathrm{a}}$ \\
\hline & P. aeruginosa & $6.0^{\mathrm{b}}$ & $7.3^{\mathrm{bc}}$ \\
& B. subtilis & $7.7^{\mathrm{c}}$ & $8.7^{\mathrm{c}}$ \\
& B. licheniformis & $5.4^{\mathrm{ab}}$ & $6.5^{\mathrm{ab}}$ \\
& $4.7^{\mathrm{a}}$ & $5.6^{\mathrm{a}}$ \\
\hline
\end{tabular}

MIC, Minimum inhibitory concentration; MBC, Minimum bactericidal concentration. 


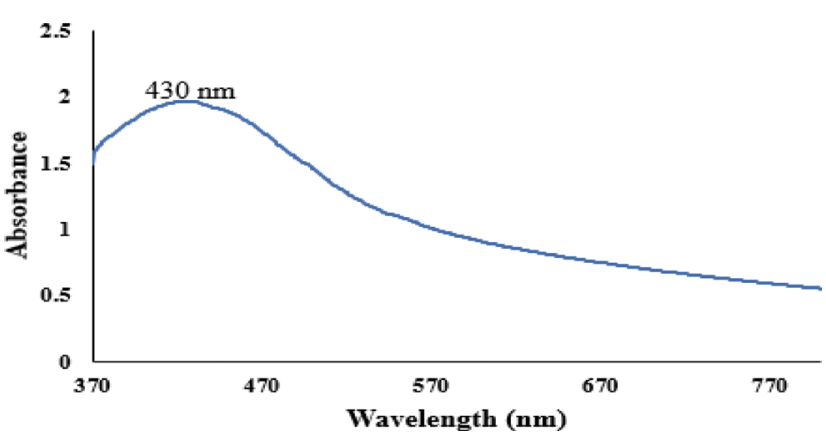

Fig. 1 UV-vis spectra of Pseudomonas aeruginosa synthesized AgNPs was showed. The formation of absorbance peek at $430 \mathrm{~nm}$ indicates the reduction of silver nitrate and the formation of AgNPs.

B. subtilis AgNPs from 4.6-6.3 $\mu \mathrm{g} / \mathrm{mL}$ and B. licheniformis AgNPs from 4.7-7.7 $\mu \mathrm{g} / \mathrm{mL}$. Regarding MBC, E. coli AgNPs showed values ranging from 7.0-11.6 $\mu \mathrm{g} / \mathrm{mL}, P$. aeruginosa AgNPs from 4.3-4.6 $\mu \mathrm{g} / \mathrm{mL}, B$. subtilis AgNPs from 5.6-6.6 $\mu \mathrm{g} / \mathrm{mL}$ and B. licheniformis AgNPs from $5.6-8.7 \mu \mathrm{g} / \mathrm{mL}$. MIC values were calculated on the basis of visual observation. The maximum $\mathrm{MIC}$ value $(8.6 \mu \mathrm{g} / \mathrm{mL})$ was noted against $E$. coli strain by $E$. coli AgNPs while lowest value was $4.3 \mu \mathrm{g} / \mathrm{mL}$ by $P$. aeruginosa AgNPs against $B$. licheniformis. Overall, $P$. aeruginosa AgNPs showed the lowest MIC and MBC values against all tested strains, hence subjected to characterization study (Table 2).

\subsection{Characterization study}

\subsubsection{UV-visible spectroscopy}

The $P$. aeruginosa AgNPs were analysed using UV visible spectrophotometer. The absorption spectrum for AgNPs was measured from 370 nm-770 nm which showed peaks from $400 \mathrm{~nm}-430 \mathrm{~nm}$. The absorption peak was observed around $430 \mathrm{~nm}$ (Fig. 1). The P. aeruginosa AgNPs showed broad peaks due to variation in the size of the NPs. Increased peak intensity is the clear indication of increased NPs in the solution.

\subsubsection{FTIR spectroscopy}

The FTIR result of $P$. aeruginosa AgNPs showed number of bands in the region 4000-500 $\mathrm{cm}^{-1}$. The spectrum analysis of AgNPs showed absorption bands at different peaks (Fig. 2). The bands present at 3261, 3061, 2947, 2358, 1338 and $1394 \mathrm{~cm}^{-1}$ corresponded to the stretching vibrations of alcohol $(\mathrm{O}-\mathrm{H})$, primary amines $(\mathrm{N}-\mathrm{H})$, alkane (C-H), amine (C-N) and alcohol (C-O) groups, respectively. Amides containing carbonyl groups $(\mathrm{C}=\mathrm{O})$ were observed at 1633 and $1575 \mathrm{~cm}^{-1}$. The other peaks at 1456, 1398 and $1072 \mathrm{~cm}^{-1}$ can be assumed to the C-O stretching vibrations aromatic and aliphatic amines, respectively (Fig. 2). The above information confirmed the presence of stabilizing agents, responsible for AgNPs stabilization.

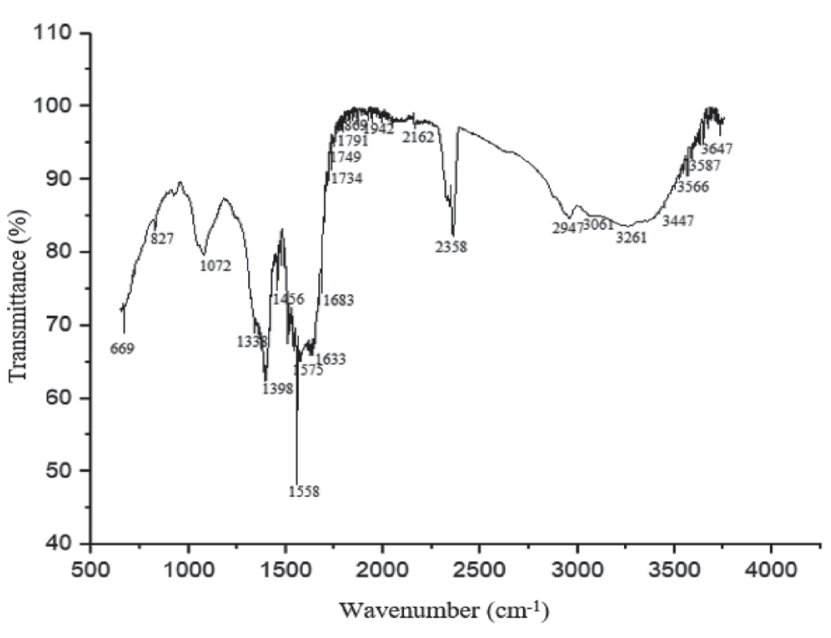

Fig. 2 FTIR spectra of Pseudomonas aeruginosa synthesized AgNPs. The different bands indicate various functional groups.

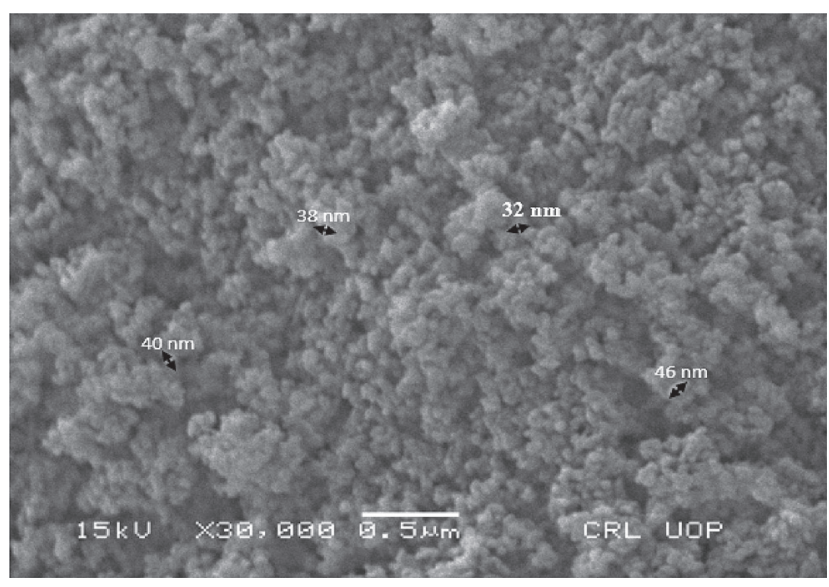

Fig. 3 SEM micrograph of Pseudomonas aeruginosa synthesized AgNPs taken at scale of $0.5 \mu \mathrm{m}$. AgNPs of spherical shape can be seen.

\subsubsection{Scanning Electron Microscopy (SEM)}

The size and morphology of $P$. aeruginosa AgNPs was examined by SEM analysis. The $P$. aeruginosa AgNPs were mostly spherical in shape with size ranging from 32-46 nm (scale bar of $0.5 \mu \mathrm{m}$ ). There were few NPs aggregation suggesting that the protein molecules may play crucial role as capping agent for NPs thus preventing agglomeration and providing stability to the synthesized NPs (Fig. 3).

\subsubsection{X-ray Diffraction (XRD)}

The XRD pattern of the $P$. aeruginosa AgNPs showed unique diffraction peaks at about $34.4^{\circ}, 46.8^{\circ}, 62.0^{\circ}$, and $79.1^{\circ}$ which indicated the presence of $111,200,220$ and 311 orientations, respectively (Fig. 4). The sharp peaks of AgNPs resulted from capping agents, which act as stabilizers for NPs. The diffraction peak present at $34.4^{\circ}$ was ascribed to the 111 lattice plane of face centred cubic (FCC), 


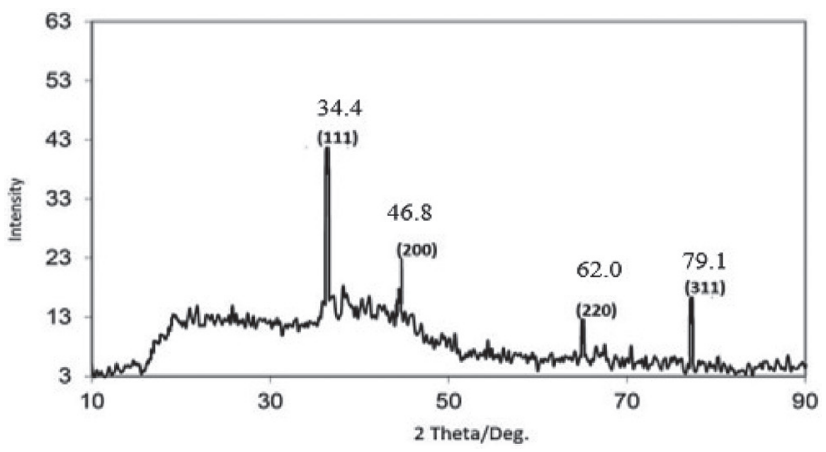

Fig. 4 XRD analysis of Pseudomonas aeruginosa synthesized AgNPs. Sharp peeks indicate the various capping agents which stabilize the AgNPs.

clearly indicated that the NPs were made up of silver (Fig. 4). The XRD pattern confirmed the crystalline nature of biogenically synthesized AgNPs.

\section{Discussion}

Biologically synthesized AgNPs have been proved as therapeutically effective and valuable compounds. They also have excellent antimicrobial and antiviral activity ${ }^{1,25,26)}$. Although, there are a lot of techniques available which can be used for the synthesis of AgNPs. Much of these techniques were focused on use of chemicals. However, green synthesis or biogenic synthesis of AgNPs is more ecofriendly approach ${ }^{26,27)}$. In the present study, four bacterial strains i.e., E. coli, P. aeruginosa, B. subtilis and B. $l i$ cheniformis were used for the biogenic synthesis of AgNPs. Synthesis of AgNPs was confirmed by color change from pale yellow to brown. Previously, Gurunathan et al. ${ }^{16)}$ described color change to brown as confirmed biogenic synthesis of AgNPs. Likewise, Masum et al. ${ }^{28)}$ reported that the formation of AgNPs get confirmed by brown coloration and more saturated brown color indicates the more AgNPs in the solution. The change in color is due to the excitation of the surface plasmon vibrations in metal $\mathrm{NPs}^{11)}$. After visual observation the solution was further analyzed by UV visible spectrophotometer.

Following formation, all four biogenically synthesized AgNPs were tested for antibacterial potential against four human isolates using agar well diffusion assay. It was observed that E. coli AgNPs showed ZOI from 16.0-19.6 mm against four isolates. P. aeruginosa AgNPs showed 19.0 to $22.5 \mathrm{~mm}$ ZOI, B. subtilis AgNPs showed 7.0 to $17.3 \mathrm{~mm}$ ZOI and B. licheniformis AgNPs showed 17.0 to $20.0 \mathrm{~mm}$ ZOI against all tested isolates. Among all biogenic AgNPs, $P$. aeruginosa AgNPs showed significant antibacterial potential even higher than positive control (rifampicin $50 \mu \mathrm{g} /$ $\mathrm{mL}$ ), because the size of $P$. aeruginosa synthesized AgNPs were 10-100 nm and showed strong antimicrobial effect against both Gram-positive and negative bacteria. The small particle size enables AgNPs to adhere to the cell wall and penetrate into the bacteria cell easily, which in turn improves their antimicrobial activity against bacteria (Table 1). The findings of this study corroborate with Aziz et $a .^{25)}$ who observed the significant antibacterial potential AgNPs
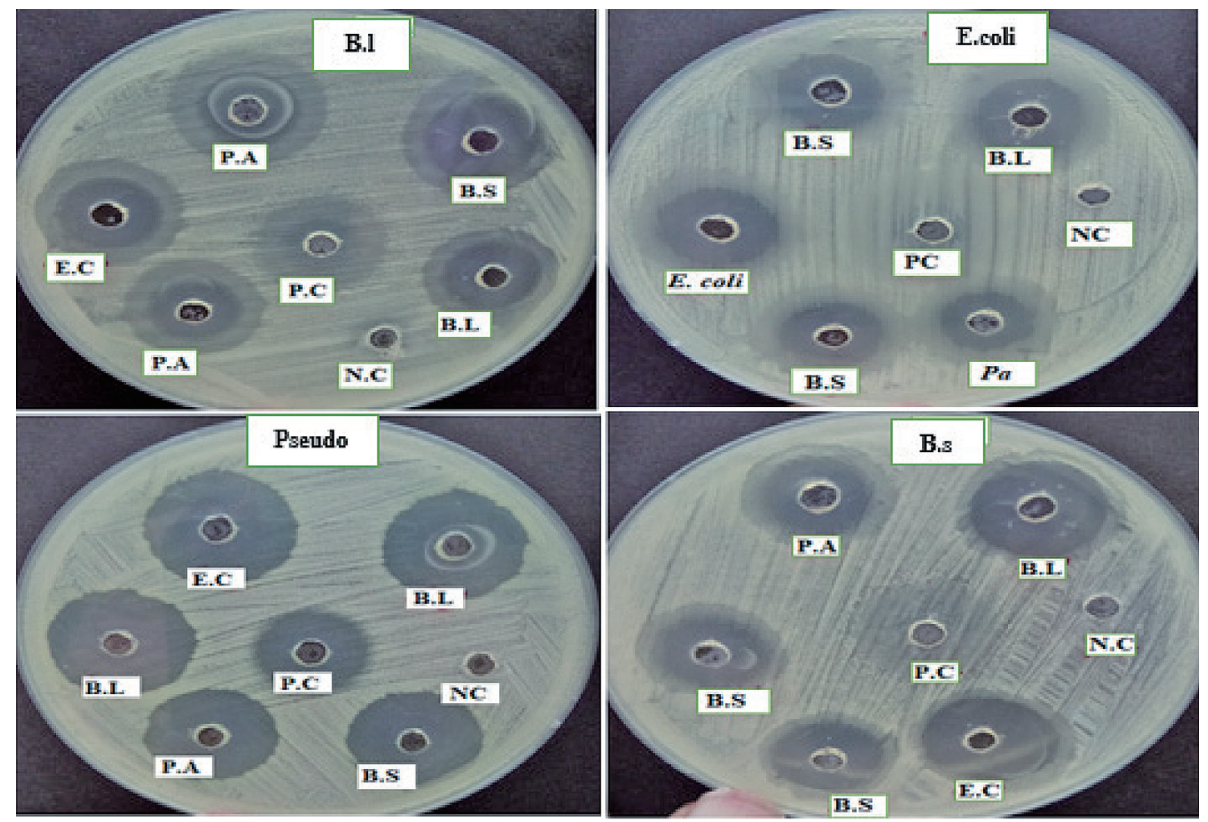

Fig. 5 The antibacterial activity of biogenically synthesized AgNPs against B. licheniformis, E. coli, P. aeruginosa and B. subtilis. The E.C; E. coli, B.S; B. subtilis, P.A; P. aeruginosa, B.L; B. licheniformis, P.C; Positive control and N.C; Negative control. 
even at lower concentration. Previously, Hamouda et al. ${ }^{29)}$ reported that AgNPs release $\mathrm{Ag}^{+}$ions from the surface and these ions are responsible for the bactericidal efficacy of AgNPs. The more $\mathrm{Ag}^{+}$ions release will kill more bacteria which results in bigger ZOI. The observed ZOI by biogenically synthesized NPs were obtained after subtracting the $\mathrm{ZOI}$ by $\mathrm{AgNO}_{3}$, hence indicating the actual antibacterial potential of biogenic NPs.

Silver nitrate has shown different effects against bacteria at high concentrations, killing bacteria by different mechanisms, which are binding to the thiol groups of protein and denaturing them, programmed cell death (apoptosis) and causing the DNA to be in the condensed form, which inhibits cell replication. While low concentrations (5-10 mM) of $\mathrm{AgNO}_{3}$ leads to the formation of silver $\mathrm{NPs}^{30)}$. This study used low concentration $10 \mathrm{mM} \mathrm{AgNO}_{3}$ for forming AgNPs. However, it's already stated that in depth antibacterial mechanism of NPs is still unclear. In particular, various bacterial isolates, their mechanism of action, resistance profile, and NP potential have been reported previously, which make it difficult to compare bacteriostatic vs bactericidal activity. In addition, no single method/criteria justify the exact through information about antibacterial mechanisms of tested $\mathrm{NPs}^{31}$.

In this study, tube dilution method was used for the determination of MIC and MBC. The maximum MIC value (8.6 $\mu \mathrm{g} / \mathrm{mL}$ ) was noted against $E$. coli by $E$. coli AgNPs while lowest value was $4.3 \mu \mathrm{g} / \mathrm{mL}$ by $P$. aeruginosa AgNPs against $B$. licheniformis. Overall, $P$. aeruginosa AgNPs showed the lowest MIC and MBC values against all tested strains, hence subjected to characterization study. The MIC values were 4.3 to $8.6 \mu \mathrm{g} / \mathrm{mL}$ against $E$. coli, 6 to $7.6 \mu \mathrm{g} / \mathrm{mL}$ against $P$. aeruginosa, 4.3 to $6 \mu \mathrm{g} / \mathrm{mL}$ against $B$. subtilis and 4.6 to $6.6 \mu \mathrm{g} / \mathrm{mL}$ against $B$. licheniformis. These results were significant $(p<0.05)$. The above results showed that AgNPs have lowest minimum inhibitory concentration against pathogenic bacteria suggesting the broad spectrum nature of their antimicrobial activity ${ }^{32)}$. The MBC values were 5.6 to $11.6 \mu \mathrm{g} / \mathrm{mL}$ against $E$. coli, 6.3 to $8.8 \mu \mathrm{g} / \mathrm{mL}$ against $P$. aeruginosa, 5.6 to $10.3 \mu \mathrm{g} / \mathrm{mL}$ against $B$. subtilis and the MIC value against $B$. licheniformis was 5.5 to $8.3 \mu \mathrm{g} / \mathrm{mL}$ (Table 2 ). The findings of this study are consistent with the results by ${ }^{33)}$.

The $P$. aeruginosa synthesized AgNPs show strong peek at $430 \mathrm{~nm}^{28)}$. The occurrence of peek around $430 \mathrm{~nm}$ indicates the presence of AgNPs. Aziz et al. ${ }^{25)}$ reported that the reduction of silver nitrate causes the occurrence of peek around 430. Biosynthetic mechanism of AgNPs has been assumed that the $\mathrm{Ag}^{+}$ions required NADPH-dependent nitrate reductase enzymes for their reduction, which were released by tested bacteria in their extracellular environment $^{34)}$.

FTIR of $P$. aeruginosa AgNPs was performed to check the involvement of biological molecules. The bands present at $3261,3061,2947,2358,1338$ and $1394 \mathrm{~cm}^{-1}$ corresponded to the stretching vibrations of alcohol $(\mathrm{O}-\mathrm{H})$, primary amines $(\mathrm{N}-\mathrm{H})$, alkane $(\mathrm{C}-\mathrm{H})$, amine $(\mathrm{C}-\mathrm{N})$ and alcohol (C-O) groups respectively, as reported previously by Liaqat $^{35)}$ and Kalyanasundaram et $a l .{ }^{36)}$. The SEM data showed that silver nanoparticles are in spherical shape with average size of $40 \mathrm{~nm}$. The formation of various sharp peeks in XRD, indicated the presence of different molecules, involved in the stabilization of the NPs. Similar result was reported by Kumar et al. ${ }^{37)}$.

\section{Conclusion}

This study showed the effective antibacterial potential of biogenically synthesized AgNPs and suggested these as alternative source of antimicrobial agents against human pathogenic bacteria. AgNPs showed strong bactericidal effect even at lower concentration against the test human pathogenic strains. Ongoing in vivo study will prove their toxicity analysis and safety in pharmaceutical and therapeutic biomedical applications.

\section{Conflict of Interests}

On behalf of all authors, the corresponding author states that there is no conflict of interest.

\section{Author Contributions}

I. Liaqat designed the project and supervised the complete study. S. Tufail did experimental work on characterization and wrote the first draft. I. Liaqat and S. Tufail did the statistical analysis. I. Liaqat wrote the final draft. S. Andleeb, S. Naseem, U. Zafar, and A. Sadiqa proof read the manuscript. I. Liaqat, N. M. Ali, A. Bibi, N. Arshad and G. Saleem helped in experimental work. All authors approved the final version of manuscript.

\section{Supporting Information}

This material is available free of charge via the Internet at doi: 10.5650/jos.ess21291

\section{References}

1) Tufail, M.S.; Liaqat, I. Silver nanoparticles and their applications-A comprehensive review. Pure Appl. Biol. 11, 315-330 (2021).

2) Cha, K.E.; Myung, H.J. Cytotoxic effects of nanoparti- 
cles assessed in vitro and in vivo. J. Microbiol. Biotechnol. 17, 1573-1578(2007).

3) Ahmed, S.; Ahmad, M.; Swami, B.L.; Ikram, S. A review on plants extract mediated synthesis of silver nanoparticles for antimicrobial applications: a green expertise. J. Adv. Res. 7, 17-28(2016).

4) Kaliamurthi, S.; Selvaraj, G.; Çakmak, Z.E.; Çakmak, T. Production and characterization of spherical thermostable silver nanoparticles from Spirulina platensis (Cyanophyceae). Phycologia 55, 568-576 (2016).

5) Satyavani, K.; Gurudeeban, S.; Ramanathan, T. Influence of leaf broth concentration of Excoecaria agallocha as a process variable in silver nanoparticles synthesis. J. Nanomed. Res. 1, 11 (2014).

6) Borrego, B.; Lorenzo, G.; Mota-Morales, J.D.; AlmanzaReyes, H.; Mateos, F.; López-Gil, E.; Bogdanchikova, N. Potential application of silver nanoparticles to control the infectivity of Rift Valley fever virus in vitro and in vivo. Nanomed-Nanotechnol. Biol. Med. 12, 11851192 (2016).

7) Benelli, G. Plant-mediated biosynthesis of nanoparticles as an emerging tool against mosquitoes of medical and veterinary importance: A review. Parasitol. Res. 115, 23-34 (2016).

8) Chari, N.; Felix, L.; Davoodbasha, M.; Ali, A.S.; Nooruddin, T. In vitro and in vivo antibiofilm effect of copper nanoparticles against aquaculture pathogens. Biocatal. Agric. Biotechnol. 10, 336-341 (2017).

9) LewisOscar, F.; MubarakAli, D.; Nithya, C.; Priyanka, R.; Gopinath, V.; Alharbi, N.S.; Thajuddin, N. One pot synthesis and anti-biofilm potential of copper nanoparticles (CuNPs) against clinical strains of Pseudomonas aeruginosa. Biofouling 31, 379-391 (2015) .

10) Morris, S.; Cerceo, E. Trends, epidemiology, and management of multi-drug resistant gram-negative bacterial infections in the hospitalized setting. Antibiotics 9, 196 (2020).

11) Sastry, M.; Ahmad, A.; Khan, M.I.; Kumar, R. Biosynthesis of metal nanoparticles using fungi and actinomycete. Curr. Sci. 85, 162-170(2003).

12) Singh, R.; Wagh, P.; Wadhwani, S.; Gaidhani, S.; Kumbhar, A.; Bellare, J.; Chopade, B.A. Synthesis, optimization, and characterization of silver nanoparticles from Acinetobacter calcoaceticus and their enhanced antibacterial activity when combined with antibiotics. Int. J. Nanomedicine 8, 4277-4290 (2013).

13) Liaqat, I.; Sabri, A.N. Effect of biocides on biofilm bacteria from dental unit water lines. Curr. Microbiol. 56, 619-624(2008).

14) Sadiqa, A.; Gilani, S.R.; Anwar, A.; Mehboob, A.; Saleem, A.; Rubab, S. Biogenic fabrication, characterization and drug loaded antimicrobial assay of silver nanoparticles using Centratherum anthalminticum
(L.) Kuntze. J. Pharm. Sci. 110, 1969-1978(2021).

15) Deepak, V.; Umamaheshwaran, P.S.; Guhan, K.; Nanthini, R.A.; Krithiga, B.; Jaithoon, N.M.H.; Gurunathan, $\mathrm{S}$. Synthesis of gold and silver nanoparticles using purified URAK. Colloids Surf. B 86, 353-358(2011).

16) Gurunathan, S.; Kalishwaralal, K.; Vaidyanathan, R.; Venkataraman, D.; Pandian, S.R.K.; Muniyandi, J.; Hariharan, N.; Eom, S.H. Biosynthesis, purification and characterization of silver nanoparticles using Escherichia coli. Colloids Surf. B 74, 328-335 (2009).

17) Singh, R.; Shedbalkar, U.U.; Wadhwani, S.A.; Chopade, B.A. Bacteriagenic silver nanoparticles: synthesis, mechanism, and applications. Appl. Microbiol. Biotechnol. 99, 4579-4593 (2015).

18) Siddiqi, K.S.; Husen, A.; Rao, R.A. A review on biosynthesis of silver nanoparticles and their biocidal properties. J. Nanobiotechnology 16, 1-28(2018).

19) Liaqat, I.; Bachmann, R.T.; Sabri, A.N.; Edyvean, R.G.; Biggs, C.A. Investigating the effect of patulin, penicillic acid and EDTA on biofilm formation of isolates from dental unit water lines. Appl. Microbiol. Biotechnol. 81, 349-358(2008).

20) Liaqat, I.; Arshad, N.; Arshad, M.; Mirza, S.A.; Ali, N.M.; Shoukat, A. Antimicrobial activity of some medicinal plants extracts against food industry isolates. Pak. J. Zool. 49, 565-572(2017).

21) Liaqat, I.; Sumbal, F.; Sabri, A.N. Tetracycline and chloramphenicol efficiency against selected biofilm forming bacteria. Curr. Microbial. 59, 212-220 (2009).

22) Liaqat, I.; Liaqat, M.; Tahir, H.M.; Ali, N.M.; Arshad, M.; Arshad, N. Motility effects biofilm formation in Pseudomonas aeruginosa and Enterobacter cloacae. Pak. J. Pharm. Sci. 32, 927-932(2019).

23) Liaqat, I.; Arshad, N.; Arshad, M.; Mirza, S.A.; Ali, N.M.; Shoukat, A. Antimicrobial activity of some medicinal plants extracts against food industry isolates. Pak. J. Zool. 49, 565-672(2017).

24) Liaqat, I. Fourier transform infrared spectroscopy of dental unit water line biofilm bacteria. Spectroscopy 23, 175-189 (2009).

25) Aziz, N.; Fatma, T.; Varma, A.; Prasad, R. Biogenic synthesis of silver nanoparticles using Scenedesmus abundans and evaluation of their antibacterial activity. J. Nanopart. Res. 2014, 689419(2014).

26) Zhang, X.F.; Liu, Z.G.; Shen, W.; Gurunathan, S. Silver nanoparticles: Synthesis, characterization, properties, applications, and therapeutic approaches. Int. J. Mol. Sci. 17, 1534(2016).

27) Iravani, S.; Korbekandi, H.; Mirmohammadi, S.V.; Zolfaghari, B. Synthesis of silver nanoparticles: Chemical, physical and biological methods. Res. Pharm. Sci. 9, 385-406 (2014).

28) Masum, M.; Islam, M.; Siddiqa, M.; Ali, K.A.; Zhang, Y.; 
Abdallah, Y.; Li, B. Biogenic synthesis of silver nanoparticles using Phyllanthus emblica fruit extract and its inhibitory action against the pathogen Acidovorax oryzae strain RS-2 of rice bacterial brown stripe. Front. Microbiol. 10, 820 (2019).

29) Hamouda, R.A.; Hussein, M.H.; Abo-Elmagd, R.A.; Bawazir, S.S. Synthesis and biological characterization of silver nanoparticles derived from the Cyanobacterium oscillatoria limnetica. Sci. Rep. 9, 1-17(2019).

30) Pandian, S.R.K.; Deepak, V.; Kalishwaralal, K.; Viswanathan, P.; Gurunathan, S. Mechanism of bactericidal activity of silver nitrate-A concentration dependent bifunctional molecule. Braz. J. Bio. 41, 805-809 (2010).

31) Wang, L.; Hu, C.; Shao, L. The antimicrobial activity of nanoparticles: present situation and prospects for the future. Int. J. Nanomedicine 12, 1227-1249(2017).

32) Ramalingam, V.; Rajaram, R.; PremKumar, C.; Santhanam, P.; Dhinesh, P.; Vinothkumar, S.; Kaleshkumar, K. Biosynthesis of silver nanoparticles from deep sea bacterium Pseudomonas aeruginosa JQ989348 for antimicrobial, antibiofilm, and cytotoxic activity. $J$. Basic Microbiol. 54, 928-936 (2014).

33) Liao, S.; Zhang, Y.; Pan, X.; Zhu, F.; Jiang, C.; Liu, Q.; Chen, L. Antibacterial activity and mechanism of silver nanoparticles against multidrug-resistant Pseudomo- nas aeruginosa. Int. J. Nanomedicine 14, 14691487 (2019).

34) Kalishwaralal, K.; Deepak, V.; Ramkumarpandian, S.; Nellaiah, H.; Sangiliyandi, G. Extracellular biosynthesis of silver nanoparticles by the culture supernatant of Bacillus licheniformis. Mat. Lett. 62, 4411-4413 (2008).

35) Liaqat, I. Fourier transform infrared spectroscopy of dental unit water line biofilm bacteria. Spectroscopy 23, 175-189 (2009).

36) Kalyanasundaram, G.T.; Doble, M.; Gummadi, S.N. Production and downstream processing of $(1 \rightarrow 3)-\beta-\mathrm{D}$ glucan from mutant strain of Agrobacterium sp. ATCC 31750. AMB Express 2, 1-10 (2012).

37) Kumar, V.; Yadav, S.K. Plant mediated synthesis of silver and gold nanoparticles and their applications. $J$. Chem. Technol. Biotechnol. 84, 151-157(2009).

CC BY 4.0 (Attribution 4.0 International). This license allows users to share and adapt an article, even commercially, as long as appropriate credit is given. That is, this license lets others copy, distribute, remix, and build upon the Article, even commercially, provided the original source and Authors are credited. 